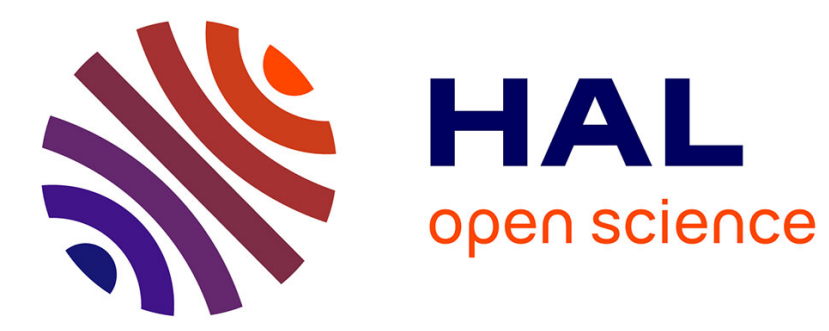

\title{
Does exist an anomalous sound dispersion in supercooled water?
}

Andrea Taschin, Riccardo Cucini, Paolo Bartolini, Renato Torre

\section{To cite this version:}

Andrea Taschin, Riccardo Cucini, Paolo Bartolini, Renato Torre. Does exist an anomalous sound dispersion in supercooled water?. Philosophical Magazine, 2010, pp.1. 10.1080/14786435.2010.522215 . hal-00637021

\section{HAL Id: hal-00637021 \\ https://hal.science/hal-00637021}

Submitted on 29 Oct 2011

HAL is a multi-disciplinary open access archive for the deposit and dissemination of scientific research documents, whether they are published or not. The documents may come from teaching and research institutions in France or abroad, or from public or private research centers.
L'archive ouverte pluridisciplinaire HAL, est destinée au dépôt et à la diffusion de documents scientifiques de niveau recherche, publiés ou non, émanant des établissements d'enseignement et de recherche français ou étrangers, des laboratoires publics ou privés. 


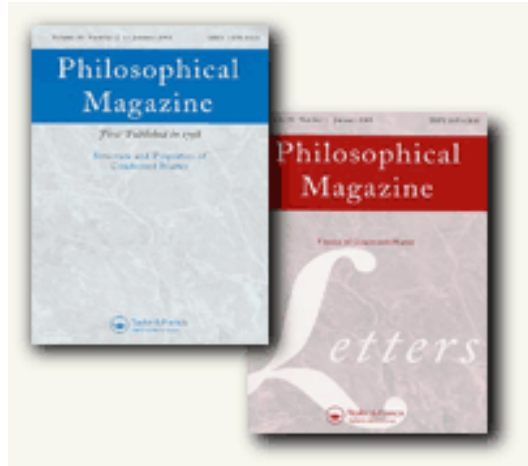

\section{Does exist an anomalous sound dispersion in supercooled water?}

\begin{tabular}{|c|c|}
\hline Journal: & Philosophical Magazine \& Philosophical Magazine Letters \\
\hline Manuscript ID: & TPHM-10-May-0183 \\
\hline Journal Selection: & Philosophical Magazine \\
\hline $\begin{array}{r}\text { Date Submitted by the } \\
\text { Author: }\end{array}$ & 14-May-2010 \\
\hline Complete List of Authors: & $\begin{array}{l}\text { Taschin, Andrea; LENS, Università di Firenze } \\
\text { Cucini, Riccardo; ELETTRA } \\
\text { Bartolini, Paolo; LENS, Università di Firenze } \\
\text { Torre, Renato; Università di Firenze, Dipartimento di Fisica }\end{array}$ \\
\hline Keywords: & supercooled liquids, spectroscopy \\
\hline Keywords (user supplied): & time resolved spectroscopy, acoustic sound velocity, water \\
\hline
\end{tabular}

\section{今scholaronE" \\ Manuscript Central}


Philosophical Magazine

Vol. 00, No. 00, 00 Month 200x, 1-4

\title{
RESEARCH ARTICLE
}

\section{Does exist an anomalous sound dispersion in supercooled water?}

\author{
A. Taschin ${ }^{\mathrm{a}}$, R.Cucini $^{\mathrm{a}}$, P.Bartolini ${ }^{\mathrm{a}}$ and R.Torre ${ }^{\mathrm{a}, \mathrm{b} *}$ \\ ${ }^{a}$ European Lab. for Non-Linear Spectroscopy (LENS), Univ. di Firenze, \\ Via N. Carrara 1, I-50019 Sesto Fiorentino, Firenze, Italy; \\ ${ }^{\mathrm{b}}$ Dip. di Fisica, Univ. di Firenze, Via Sansone 1, I-50019 Sesto Fiorentino, Firenze, Italy
}

(May 2010)

\begin{abstract}
Acoustic sound velocity of water in the supercooled regime shows a peculiar behaviour. Accordingly to the available data, sound velocity displays a complex behaviour below $-15{ }^{\circ} \mathrm{C}$, here anomalous frequency dispersion phenomena seem to appear and need to be understood. In particular lower frequencies data at a few tens of $\mathrm{KHz}$ show leveling-off of the sound velocity value below $-25{ }^{\circ} \mathrm{C}$, with a possible minimum around $-30{ }^{\circ} \mathrm{C}$. Other data at higher frequencies, around $1 \mathrm{GHz}$, in comparison with the low frequency data, could instead suggest the existence of a "negative dispersion", yet other high frequency data show a normal dispersion behaviour. To get new insight into this topic, we made measurements of acoustic sound velocity in bulk water in the liquid and supercooled phase down to $-29^{\circ} \mathrm{C}$ by means of a heterodyne detected transient grating (TG) experiment at an unexplored frequency value
\end{abstract} around $100 \mathrm{MHz}$.

Keywords: supercooled water; sound velocities; transient grating; 78.47.+p; 78.40.Dw; 61.20.Ne; 61.20.Lc; 43.30.Es; 43.35.Bf;

\section{Introduction}

Despite the paramount interest of water, many physic properties of this liquid remain to be clarified [1]. In particular, several thermodynamic and dynamic features exhibit an anomalous dependence on temperature in the water supercooled phase [1-6]. Since the discover of these anomalies, the liquid matter community is puzzling about the nature and origin of these water unexpected phenomena. Different physic models has been introduced in order to describe the complex water scenario [6], nevertheless many relevant questions are still open and further research investigations are required [7]. In the liquid and supercooled water also the acoustic phenomena show peculiar and specific behaviours. These have been discussed in many research papers, for a review see [7,8]. Considering only the low wave-vector/frequency range $\left(q<50 \mu^{-1}\right.$ and $\left.\nu<10 \mathrm{GHz}\right)$, the main striking effect is the steep decrease with decreasing temperatures of the adiabatic sound velocity [9], opposite to the normal liquid trend. For $T>-15{ }^{\circ} \mathrm{C}$, this decrease does not display any dispersion phenomena (i.e. its temperature slope is independent from the sound wave-vector/frequency). Below this temperature, accordingly to the available data, the sound displays a complex behaviour where the dispersion phenomena need to be clarified [7]. In particular the lower frequency measurements $(54 \mathrm{KHz})[10-12]$ show a quite surprising phenomena: a leveling-off of the sound velocity below $-25{ }^{\circ} \mathrm{C}$, with a possible minimum around $-30{ }^{\circ} \mathrm{C}$. A comparison of

${ }^{*}$ Corresponding author. Email: torre@lens.unifi.it

ISSN: 1478-6435 print/ISSN 1478-6443 online

(C) 200x Taylor \& Francis

DOI: $10.1080 / 1478643 Y Y x x x x x x x x$

http://www.informaworld.com 

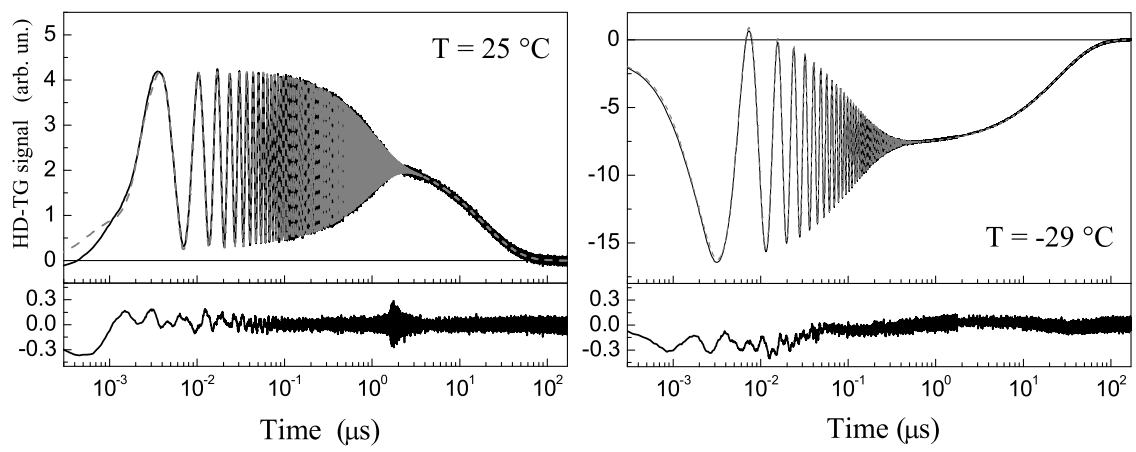

Figure 1. HD-TG data on water at $q=0.630 \mu m^{-1}$ at two different temperatures. The data show acoustic oscillations and slow thermal exponential decay. Comparison between data and fit (dashed line) is also reported. The fit is hardly visible, so we report also the residuals obtained by the difference between data and fit in an amplified scale.

these data with sound velocities obtained at higher frequencies $(\geq 900 \mathrm{MHz})[13-$ 18], produces an even more confused scenario that could suggest the existence of a "negative dispersion" (sound velocity would decrease with increasing frequency) in the water supercooled phase $[7,9,13,16]$. We performed a transient grating (TG) experiment on the supercooled phase of bulk water down to $-29{ }^{\circ} \mathrm{C}$, extending the previous investigation [9] for more then 10 degrees in the supercooled phase. The TG experiment enables us to measure the sound velocity of water in a frequency range $(100 \mathrm{MHz})$ previously unexplored and particular meaningful in order to clarify the summarized complex scenario.

\section{Experiments and data}

The experimental details has been described in previous paper [9], here we recall the main characteristics. In a transient grating experiment with heterodyne detection (HD-TG) two infrared laser pulses interfere within the sample to produce a spatial modulation of the dielectric constant. The relaxation of the induced transient modulation is probed by the Bragg scattering of a third laser beam, typically of different wavelength. The diffracted beam is then beaten with a local field in order to obtain the heterodyne detection. In the HD-TG experiment used here, the infrared pump pulses had a $1064 \mathrm{~nm}$ wavelength, a temporal length of 20 ps and repetition rate of $10 \mathrm{~Hz}$ (Nd-YAG EKSPLA PL2143). The typically used pump pulse energy was $5 \mathrm{~mJ}$. The probing beam, instead, was a continuous-wave laser at $532 \mathrm{~nm}$ produced by a diode-pumped intracavity-doubled Nd-YVO (Verdi-Coherent). The heterodyne signal was detected by a fast avalanche photodiode with a bandwidth of $1 \mathrm{GHz}$ (APD, Hamamatsu) and amplified with a DC-800 MHz AVTECH amplifier. After that it was recorded by a digital oscilloscope with a bandwidth of $7 \mathrm{GHz}$ at a sampling rate of $20 \mathrm{Gs} / \mathrm{s}$ (Tektronix TDS7704B). We performed the measurements on sealed vial of cylindrical shape, prepared for pharmaceutical purposes by Angelini company, that allows to reach a temperature of $-29{ }^{\circ} \mathrm{C}$. In the experimental set-up, the sample temperature is controlled by a home-made cryostat with a stability of $0.1{ }^{\circ} \mathrm{C}$. The vial is inserted into an aluminium holder fixed to the cold plate of a Peltier cooler; the temperature is controlled by a platinum thermo-resistance in thermal contact with the aluminium holder. The HD-TG measure the material response function that according to the hydrodynamic models can be connected to the density time evolution $[9,19]$. In this specific case, the measured signal can be 


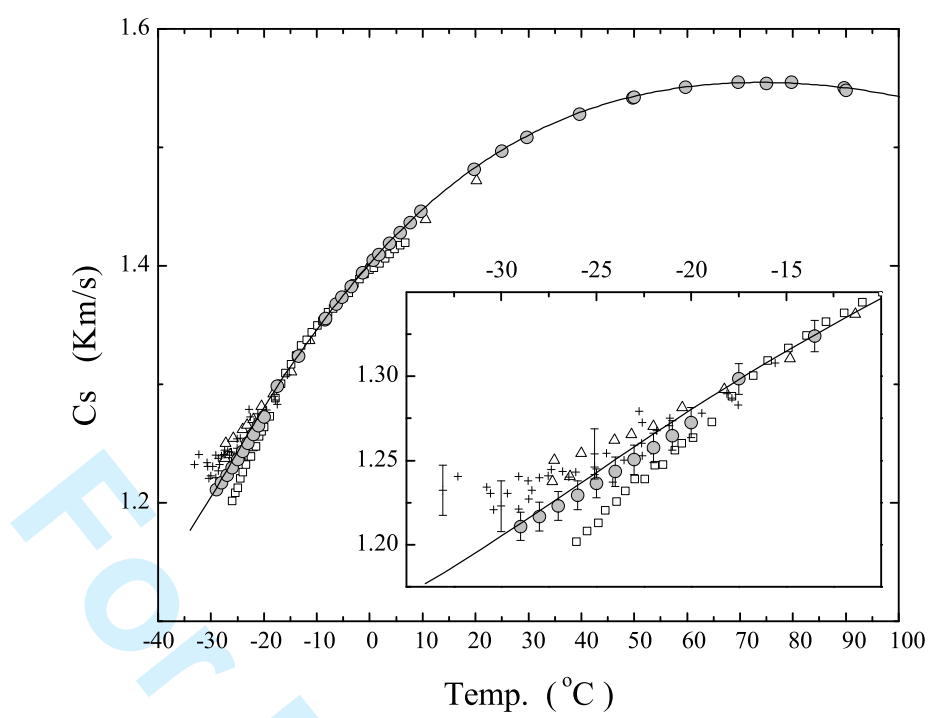

Figure 2. Temperature dependence of the water sound velocity. Our data $(\bullet)$ are compared with other measurements. Ultrasonic data: at $54 \mathrm{KHz}(+)$ from Ref. [12], at $925 \mathrm{MHz}(\square)$ from Ref.[20]. Light scattering data: at $1.27 \mathrm{GHz}(\Delta)$ from Ref.[17]. In the inset we report a magnification of the low temperature data, where the unexpected dispersion effect for ultrasonic data clearly appears. The continuous line correspond to the hydrodynamic adiabatic sound velocities calculated using the thermodynamic values.

cast in the following form:

$$
S^{H D-T G}(q, t) \propto A e^{-\Gamma t} \cos [\omega(q) t]+B e^{-\Gamma t} \sin [\omega(q) t]+C e^{-\Gamma_{T} t}
$$

where $\omega, \Gamma$ are the sound frequency and damping rate and $\Gamma_{T}$ the thermal damping rate. The full definition of the hydrodynamic model and the fitting procedure is reported in ref. [9]. The signal definition, reported in eq.1, enables a very good fit of the HD-TG data, see fig.1. Performing the fit of all TG data we obtained the temperature dependence of the water sound velocities, see fig.2. In particular we report the measurement of the water sound velocity for $q=0.63 \mu \mathrm{m}^{-1}$, corresponding to a frequency of about $f=\omega / 2 \pi \simeq 140 \mathrm{MHz}$. Our data show a very good agreement with all reported data confirming that there is no dispersion effects in the liquid and weakly supercooled water, over $\approx-15{ }^{\circ} \mathrm{C}$. Indeed the sound velocity data from literature in the supercooled region below $-15^{\circ} \mathrm{C}$ are quite misleading. In fact, the very low frequency data $(\sim 50 \mathrm{KHz})[12]$ are in very good agreement with the light scattering data [17] corresponding to a much higher frequency $(\sim 1$ $\mathrm{GHz}$ ), furthermore this data show a flattening versus the low temperature. Vice versa other ultrasonic data [20] characterized by an intermediate frequency $(\sim 900$ $\mathrm{MHz})$ show a clear departure. Our data $(\sim 100 \mathrm{MHz})$ report sound velocities below the light scattering data $(\sim 1 \mathrm{GHz})$ ( $\triangle$ in figure 2$)$, as expected for normal sound dispersion, but surely over the $\sim 900 \mathrm{MHz}$ data ( $\square$ in figure). The sound velocities from our TG data are compatible within the error bars with the $\sim 50 \mathrm{KHz}$ data (+ in figure), but they show a much weaker bending of the slope.

\section{Discussion}

The positive dispersion that is observed in the light scattering measurement of $C_{s}$ at relatively high-frequencies (around 1-10 GHz) must be addressed to dynamic 
processes $[17,18]$. The increase of sound velocity with increasing frequency is due to the viscoelastic processes connected with structural relaxation time. The expected structural relaxation times, for the lower temperatures analysed, is of the order of about ten picoseconds [21] corresponding to a factor $\tau \omega \sim 0.1$ for a frequency of $5 \mathrm{GHz}$. This value is small but not negligible in order to consider the sound velocity totally hydrodynamic. The same argument can not be applied to understand the lower frequencies sound velocities data that should be interpreted by purely thermodynamic model. In fact the hydrodynamic sound velocity is completely defined by the thermodynamic parameters, being $C_{0}=\sqrt{\frac{1}{\rho K_{T}} \frac{c_{p}}{c_{v}}}$, where $\rho$ is the mass density, $K_{T}$ is the isothermal compressibility, $c_{p}$ and $c_{v}$ are the isobaric and isochoric specific heats, respectively [7]. The $50 \mathrm{KHz}$ sound data have been compared with a calculation of $C_{0}$ reporting a minimum around of it around -25 C. We repeated such calculation using more recent thermodynamic data and the relation $c_{v}=c_{p}-v T \frac{\alpha^{2}}{K_{T}}$, being $\alpha$ the thermal expansivity. The utilized thermodynamic data $\rho$ and $\alpha$ are from [22], $K_{T}$ and $c_{p}$ from [23]. As it is clear from figure 2 our data are in very good agreement with the thermodynamic calculation of $C_{0}$. This is proving that the low frequency $(\sim 100 \mathrm{MHz})$ sound velocities in supercooled water does show a purely thermodynamic nature and its temperature dependence is correctly defined by the combination of well known anomalies present in the thermodynamic parameters. According to our data the leveling-off of the sound velocity is doubtful. If it exist, it is surely much weaker that reported in the previous works [10-12]. Moreover, the ultrasonic data ( $900 \mathrm{MHz})[13]$ seems affected by some experimental drawback that produces a systematic reduction of the velocities. So trying to give an answer to the question stated in the title, does not exist a negative dispersion phenomena in the supercooled water and the sound starts to display a positive dispersion, due to the structural relaxation processes, for frequencies $\geq 1 \mathrm{GHz}$.

\section{References}

[1] P. Debenedetti and H.E. Stanley, Physics Today 56 (2003) p.40.

[2] C. Angell, Annu. Rev. Phys. Chem. 34 (1983) p.593-630.

[3] P.H. Poole, F. Sciortino, U. Essmann and H.E. Stanley, Nature 360 (1992) p.324-328.

[4] O. Mishima and H. Stanley, Nature 396 (1995) p.329-335.

[5] F. Sciortino, P. Gallo, P. Tartaglia and S.H. Chen, Phys. Rev. E 54 (1996) p.6331-6343.

[6] P.G. DeBenedetti Metastable liquids, Oxford: Pergamon, 1996.

[7] P. Debenedetti, J. Phys.: Cond. Matt. 15 (2003) p.R1669-R1726.

[8] G. Ruocco and F. Sette, J. Phys.: Cond. Matt. 11 (1999) p.R259.

[9] A. Taschin, P. Bartolini, R. Eramo and R. Torre, Phys. Rev. E 74 (2006) p.031502.

[10] E. Trinh and R. Apfel, J. Acoust. Soc. Am. 63 (1978) p.777.

[11] E. Trinh and R. Apfel, J. Chem. Phys. 69 (1978) p.4245.

[12] E. Trinh and R. Apfel, J. Chem. Phys. 72 (1980) p.6731.

[13] J. Rouch, C.C. Lai and S.H. Chen, J. Chem. Phys. 65 (1976) p.4016

[14] J.L. O. Conde and J.Teixeira, J. Physique 41 (1980) p.997.

[15] J. O. Conde and P.Papon, J. Chem. Phys. 76 (1982) p.3747.

[16] G. Maisano, P. Migliardo, F. Aliotta, C. Vasi, F.Wanderlingh and G. D'Arrigo, Phys. Rev. Lett. 52 (1984) p.1025.

[17] S. Magazu, G. Maisano, D. Majolino, F. Mallamace, P. Migliardo, F. Aliotta and C. Vasi, J. Phys. Chem. 93 (1989) p.942-947.

[18] A. Cunsolo and M. Nardone, J. Chem. Phys. 105 (1996) p.3911-3917.

[19] A. Taschin, R. Eramo, P. Bartolini and R. Torre, 2008, Transient grating experiments in glass-former liquids. in Time-resolved spectroscopy of complex liquids Springer, New York, p. 129.

[20] J.C. Bacri and R. Rajaonarison, J. Physique 40 (1979) p.L-403.

[21] R. Torre, P. Bartolini and R. Righini, Nature 428 (2004) p.296-299.

$[22]$ D. Hare and C. Soreson, J. Chem. Phys. 87 (1987) p.4840-4845.

[23] R. Speedy, J. Phys. Chem. 91 (1987) p.3354-3358. 